\title{
Blue light-emitting carbon dots (CDs) from a milk protein and their interaction with Spinacia oleracea leaf cells
}

\author{
S. K. Bajpai ${ }^{1} \cdot$ A. D'Souza ${ }^{2} \cdot$ Basharat Suhail $^{1}$
}

Received: 19 November 2018 / Accepted: 9 April 2019 / Published online: 20 April 2019

(c) The Author(s) 2019

\begin{abstract}
The milk protein casein (Cas) has been employed as carbon resource material to synthesize nitrogen-doped carbon dots ( $\mathrm{N}-\mathrm{CDs}$ ) via microwave exposure. The dots, when exposed to UV light, produced blue fluorescence. The N-CDs were characterized by ultra violet (UV) spectroscopy, Fourier transformation infrared spectroscopy, X-ray diffraction (XRD), dynamic light scattering analysis, fluorescent microscopy (FM), and transmission electron microscopy (TEM). The XRD analysis revealed a broad peak at $2 \theta=20^{\circ}$, thus indicating the turbostratic carbon phase. TEM analysis and particle size distribution curve revealed that nearly, $85 \%$ of the particles had diameter below $10 \mathrm{~nm}$ and the particles had spherical geometry. The HRTEM analysis revealed that carbon dots exhibited lattice fringes with a d-spacing of $0.21 \mathrm{~nm}$, corresponding to the (100) plane lattice of graphite. The fluorescence spectral studies indicated a red shift in the emission peak from 420 to $450 \mathrm{~nm}$ as the excitation wavelength increased from 300 to $340 \mathrm{~nm}$. The zeta potential of particles was found to be $-11.3 \mathrm{mV}$. Finally, impregnation of N-CDs was studied in Spinacia oleracea leaf. It was observed that as the concentration of N-CDs' solution increased, percent insertion (PI) also increased, but the time required for maximal insertion decreased with increasing concentrations of N-CDs in the feed solutions. In the carbon dots' solution with a concentration of $200 \mathrm{ppm}$, maximum percent insertion (MPI) was obtained after $80 \mathrm{~min}$. However, with the increasing concentration of N-CDs in the feed solutions, time of getting MPI reduced, i.e., in $600 \mathrm{ppm}$, it was $30 \mathrm{~min}$, and in $800 \mathrm{ppm}$, it was $10 \mathrm{~min}$.
\end{abstract}

Keywords Carbon dots $\cdot$ Fluorescence $\cdot$ Casein $\cdot$ Plant cells

\section{Introduction}

Since their invention in the year 2004, carbon dots have emerged out as a new class of nanomaterial that possess remarkable properties such as fair hydrophilic nature, excellent biocompatibility [1], cell permeability, photo stability, etc. $[2,3]$. Owing to these properties, carbon dots (CDs) have tremendous potential to be used in a number of applications such as cell imaging and sensing [4-6]. Fluorescence

S. K. Bajpai

sunil.mnlbpi@gmail.com

A. D’Souza

anjalidsouza@rediffmail.com

Basharat Suhail

basharatsuhail@gmail.com

1 Polymer Research Laboratory, Department of Chemistry, Govt. Model Science College, Jabalpur, MP 482001, India

2 Department of Chemistry, St. Aloysius College, Jabalpur, MP 482001, India carbon nanoparticle (CNP) shows high potential in biological labeling, bio-imaging and other different optoelectronic device application $[7,8]$, targeted drug delivery $[9,10]$ in cancer theranostics $[11,12]$, and drug delivery [13]. In addition to this, they find multiple applications in analytical chemistry [14]. Carbon dots (CDs), generally known to be discrete, quasi-spherical particles with sizes below $10 \mathrm{~nm}$, possess a $\mathrm{sp}^{2}$ conjugated core superimposed by functionalities such as carboxyl, aldehyde, ketone, etc. which depend upon the nature of carbon resource material used to prepare carbon dots. In recent years, there have been sincere attempts to tune the fluorescence efficiency of carbon dots by doping of elements such as sulfur and/or nitrogen [15]. It has been reported that carbon dots, when doped with nitrogen, show excellent optical properties and demonstrate blue shift in fluorescence [16]. Amino acids, due to their low cost and abundance, are frequently used as carbon and nitrogen sources. In addition, primary amines not only provide nitrogen, but they also passivate the carbon dots surface [17]. Indeed, there are several reports in recent past about the synthesis of $\mathrm{N}$-doped 
carbon dots. For example, Tan et al. have prepared N-doped CDs pyrolytically from graphene quantum dots using polysaccharide chitosan as a precursor [18]. Similarly, in a most recent work [19], N-doped carbon dots were prepared by an economical and straight forward approach which consists of hydrothermal treatment of poly(acrylamide) as both carbon and nitrogen sources. Likewise, Li et al. have reported synthesis of $\mathrm{N}$-doped carbon dots using 1,2-diaminobenzene as the carbon source and dicyandiamide as the dopant [20]. The nitrogen-doped CDs resulted in improvement in the electronic characteristics and surface chemical activities. In an interesting work by Liao et al., $\mathrm{N}$ - and S-doped carbon dots have been prepared directly from citric acid and thiamine hydrochloride via a one-step hydrothermal protocol in $63.8 \%$ quantum yield [21].

Beta casein, obtained from cow milk, is a major protein constituent of milk and it contains 209 amino acids [22]. It is a natural resource of carbon and nitrogen and has been employed in the current work to prepare carbon dots via microwave-assisted approach. The rationale for the selection of beta casein as starting material was the fact that it could provide carbon dots doped with nitrogen, and therefore, no other doping agent was required. In addition, a survey of the literature reveals that casein-derived N-CDs have not been reported for plant cell interaction investigations. It is also worth mentioning here that Casein contains a number of functional groups, and therefore, $\mathrm{N}$-CDs prepared must have varying sizes and they should exhibit broad-band emission at several excitation wavelengths. However, we focused only on blue light emissions just with an idea in mind that these N-CDs in solution form could be used as invisible ink for loading important information and advanced anti-counterfeiting.

\section{Experimental}

\section{Materials}

Beta casein was purchased from Hi Media Chemicals, Mumbai, India and was analytical grade. The de-ionized water was used throughout the investigations. The reference material quinine sulphate was purchased from obtained from D.D. Fine Chemicals, Mumbai, India and was used as received.

\section{Methods}

\section{Preparation of nitrogen-doped carbon dots (N-CDs)}

In a typical protocol, pre-determined quantity of casein was dispersed in distilled water under vigorous stirring to obtain uniform dispersion. Now, the dispersion was allowed to be exposed to microwaves, using a microwave oven (LG, model No. CE1041DFB, USA) for a total duration of $30 \mathrm{~min}$, allowing a $15 \mathrm{~s}$ exposure after every $2 \mathrm{~min}$ interval so as to avoid excessive heating. After the semi-solid residue was obtained, it was further diluted with distilled water to make a total volume of $50 \mathrm{ml}$. The above solution was centrifuged at a rate of $5000 \mathrm{rpm}$ (Remi, India) for a period of $15 \mathrm{~min}$. The supernatant was collected and used for further studies.

\section{Characterization}

The carbon dots were characterized by various analytical techniques such as Fourier Transform Infrared Spectroscopy (FTIR) using spectrophotometer (Shimadzu8400, Japan), UV-Vis spectroscopy with Elico (India), and zeta-potential measurement (Beckman Coulter Delso Nano C). The X-ray diffraction (XRD) analysis was carried out on a Rikagu diffractometer $(\mathrm{Cu}$ radiation $=0.1546 \mathrm{~nm})$ running at $40 \mathrm{kV}$ and $40 \mathrm{~mA}$. The diffractogram was recorded in the range of $2 \theta$ from 10 to 500 at the speed rate of $2 \% \mathrm{~min}$. The Transmission Electron Microscopy (TEM) analysis was carried out in Indian Institute of Technology (IIT, Mumbai, India).

\section{Determination of quantum yield (QY)}

To determine the quantum yield (QY) of the carbon dots, quinine sulphate (QS) was prepared in $0.1 \mathrm{M} \mathrm{H}_{2} \mathrm{SO}_{4}$ and employed as standard at the wavelength of $340 \mathrm{~nm}$ [23]. In a typical method, solutions of QS and N-CDs (prepared in distilled water) of varying concentrations were prepared and their absorbance was recorded. Due care was taken that their absorbance was always less than 0.1. Now, the integrated photoluminescence intensities were plotted against corresponding absorbance. The slopes of the linear plots were used to calculate QY using the following expression:

$\mathrm{QY}_{\text {sample }}=\mathrm{QY}_{\text {std }}\left[(m)_{\text {sample }} /(m)_{\text {std }}\right]\left(\eta_{\text {sample }}^{2} / \eta_{\text {std }}^{2}\right)$,

where $(m)_{\text {sample }}$ and $m_{\text {std }}$ are the slopes obtained from linear plots, $\eta_{\text {sample }}$ is the refractive index of solvent used for carbon dots (i.e., water), and $\eta_{\text {std }}$ is the refractive index of the solvent used for dissolving QS. Moreover, the quantum yield $\left(\mathrm{QY}_{\text {std }}\right)$ of standard quinine sulphate was taken as 0.54 and the refractive index $\left(\eta_{\mathrm{std}}\right)$ of QS solution, prepared in $0.1 \mathrm{M}$ $\mathrm{H}_{2} \mathrm{SO}_{4}$ was taken as 1.33 .

\section{Fluorescent microscopy}

To image the carbon dots in fluorescent microscope (Florescent Microscope, Thermo Fisher Scientific Model No. EVOS FLoid Cell Imaging Station), a drop of mounting medium was mounted on the microscope slide and coverslip 
was laid with the cells upside down on this drop. The specimen was pressed with the tweezers slightly, so that the mounting medium was well distributed, without squeezing the sample. The volumes were chosen in a way that the coverslips were completely moistened. After focusing, viewing and zooming, the (sample) slide in fluorescent microscopic, the images were captured.

\section{Insertion of carbon dots in plant tissue}

The leaves of spinach were collected, sterilized, washed with distilled water, and finally air dried. The leaves were then chopped into $5 \mathrm{~mm}$ pieces and suspended into solutions of N-CDs with different concentrations. The samples were removed at definite time intervals and washed with distilled water; slides were then prepared for imaging. The leaves, immersed in different solutions, were imaged at different time intervals.

\section{Results and discussion}

\section{Preparation of N-CDs}

Microwave-assisted synthesis is reported to be a versatile technique and provides a convenient synthetic route with additional advantage like uniform heating and keeping full control over the synthesis process. The overall scheme of formation of N-CDs is shown in Fig. 1. The microwaves provide uniform heating and the particles obtained are expected to have a narrow size distribution. Recently, a number of reports have appeared that describe CDs' synthesis via microwave exposure. For example, $\mathrm{Li}$ et al. prepared nitrogen and phosphorus co-doped carbon dots (N,P-C dots) using microwave-supported thermolysis of N-phosphonomethylaminodiacetic acid and ethylenediamine. N,P-C dots exhibited bright blue fluorescence with an emission maximum at $418 \mathrm{~nm}$ [24]. Similarly, in an interesting work by $\mathrm{He}$ et al, nitrogen-doped CDs (N-doped CDs) were synthesized by microwaves exposure of L-glutamic acid as the sole

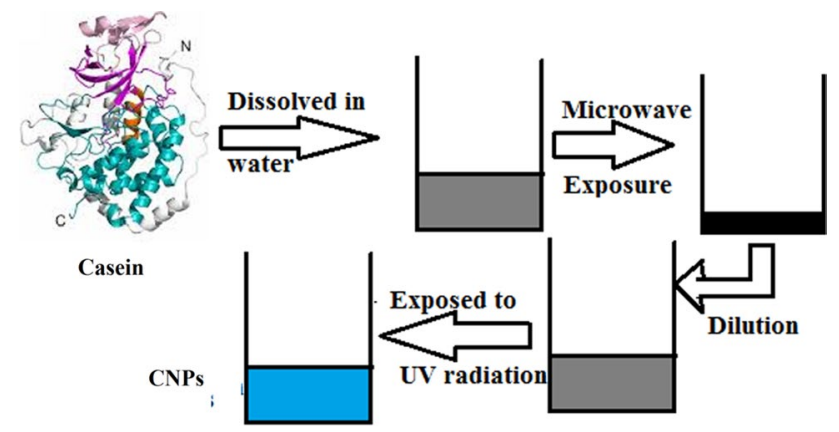

Fig. 1 Overall scheme of formation of N-CDs reaction precursor in the solid-phase condition. The $\mathrm{N}$-doped CDs, prepared within $8 \mathrm{~min}$, had an average size of $1.64 \mathrm{~nm}$ [25].

It is worth mentioning here that a proper selection of microwave power and exposure time plays a significant role in inducing photoluminescence in carbon dots and in controlling their size as well. In preliminary investigations, we used $300 \mathrm{~W}$ microwaves, keeping the temperature range of $110-130{ }^{\circ} \mathrm{C}$. However, we did not get any emission of fluorescence. Therefore, we increased the power of microwaves to $450 \mathrm{~W}$ and the temperature was kept in the range of $140-180^{\circ} \mathrm{C}$. This resulted in carbon dots with fair luminescence. It appears that a low temperature of reaction mixture may not be sufficient to cause appreciable carbonization of material to produce luminescent carbon nanoparticles.

\section{Quantum yield}

The QY was determined from the slope of the linear plot obtained between integrated photoluminescence intensities and corresponding absorbance, as shown in Fig. 2. The value of $Q Y_{\text {std }}$ for the standard sample of quinine sulphate was 0.54 . The QY of carbon dots was found to be around $18.7 \%$. The value obtained was quite similar to that reported by Tabaraki and Sadeghinejad who synthesized carbon dots from citric acid, urea, and thiourea by microwave-assisted method and reported QY of 19.2\% [26]. Similarly, Wang et al. obtained dual functional carbon dots, designated as N/ $\mathrm{Cl}-\mathrm{CDs}$, with the assistance of a choline chloride-glycerine deep eutectic solvent (DES) and reported a QY of 16.15 [27].

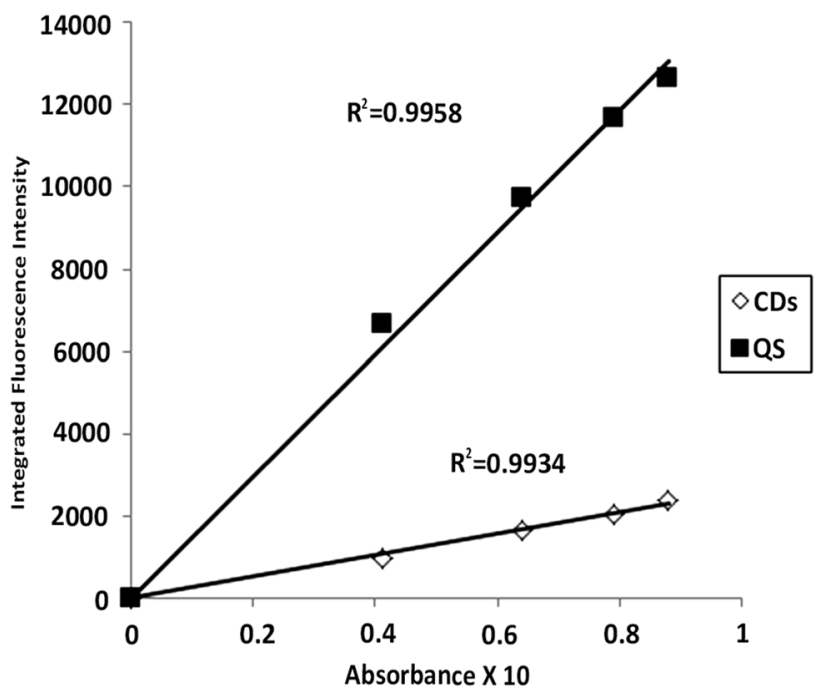

Fig. 2 Integrated fluorescence intensity versus absorbance plot of C-dots and quinine sulphate 


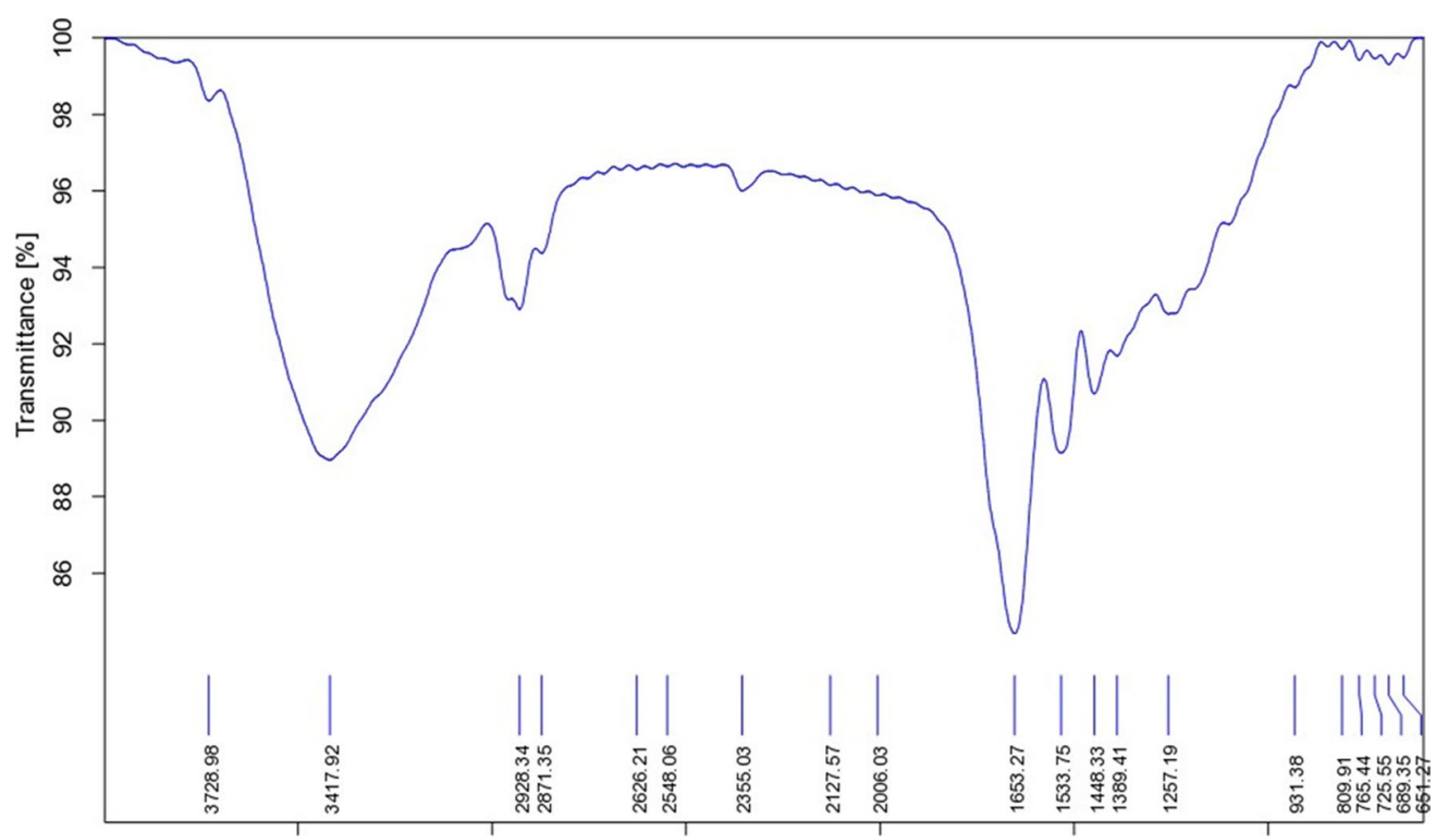

Fig. 3 FTIR spectrum of N-CDs from casein

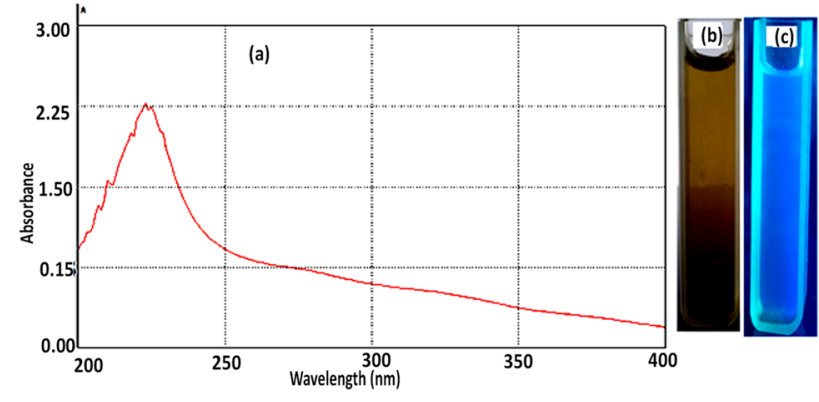

Fig. 4 a UV spectrum of N-CDs' solution, b optical images of solution in the presence of $\mathbf{b}$ sun light, and $\mathbf{c}$ UV light

\section{Characterization of $\mathrm{N}-\mathrm{CDs}$}

The FTIR spectrum of N-CDs is shown in Fig. 3. It may be noticed that a broadband appears in the range of $3000-3450 \mathrm{~cm}^{-1}$, thus indicating the presence of H-bonded surface hydroxyls. In addition, characteristic peaks of casein appear at 2920 and $2850 \mathrm{~cm}^{-1}$ due to symmetric and antisymmetric stretching of $\mathrm{CH}_{2}$. They indicate the presence of amino acids such as lysine [28]. The $\mathrm{C}=\mathrm{O}$ stretching also appears at $1728 \mathrm{~cm}^{-1}$. Finally, $\mathrm{C}-\mathrm{H}$ deformation is also indicated at $1427 \mathrm{~cm}^{-1}$.

The electronic spectroscopy offers a simple way to characterize carbon dots. The UV spectrum of carbon dots is shown in Fig. 4a. It can be seen that there is sharp peak observed around $220 \mathrm{~nm}$ along with a shoulder at $260 \mathrm{~nm}$,

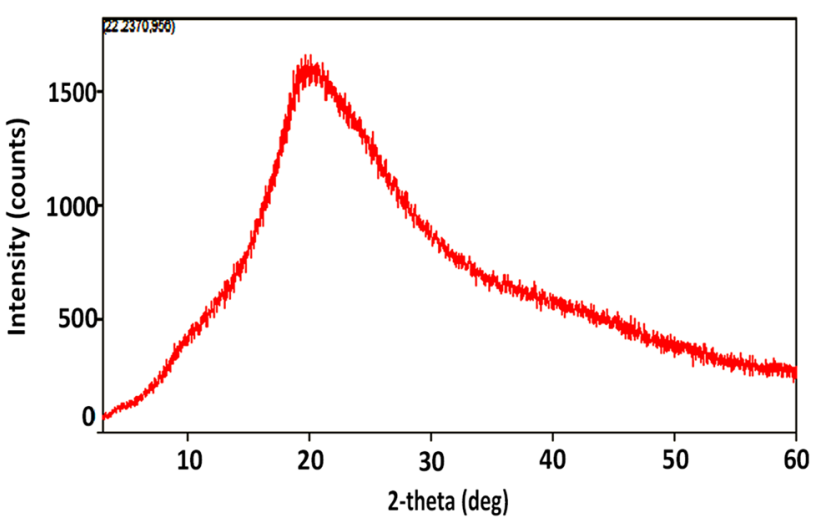

Fig. 5 XRD analysis of N-CDs

thus corresponding to $\pi-\pi^{*}$ and $n-\pi^{*}$ transitions, respectively [29]. Gowthaman et al. also observed similar transitions in electronic spectra of $\mathrm{N}$-doped carbon dots obtained from pyrolysis of L-asparagine [30]. However, the peak and the shoulder was observed at 207 and $307 \mathrm{~nm}$, respectively. Similar results are also reported elsewhere [31, 32]. The quartz cell, containing CDs' solution fluorescence, did not show any fluorescence in the presence of sun light, while a blue florescence was observed in the presence of ultra violet radiations, as shown in Fig. 4b, c, respectively.

The XRD pattern of the as-prepared casein N-CDs, as shown in Fig. 5, exhibits a broad diffraction peak centered at $2 \theta=20^{\circ}$, which is attributed to the turbostratic carbon 
phase. These results are in fair agreement with the one obtained by Lu et al. who prepared $\mathrm{N}$-doped carbon dots from hydrothermal treatment of citric acid in the presence of poly ethylenimine and reported a $2 \theta$ value of $20^{\circ}$ for CDs [33]. In an almost similar report, [34], XRD analysis of CDs obtained from hydrothermal treatment of sodium citrate and poly(acrylamide) exhibited a broad low intensity diffraction peak at $20.66^{\circ}$, indicating existence of amorphous carbon. Similarly, He et al. prepared carbon dots from sodium salt of EDTA and reported a broad peak around $24.4^{\circ}$, corresponding to $0.363 \mathrm{~nm}$ interlayer spacing of CDs. No sharp peaks were observed in the XRD patterns, confirming the amorphous character [35].

TEM analysis was carried out to determine the size of the N-CDs. The results, as shown in Fig. 6a, suggest that maximum number of particles had diameter below $10 \mathrm{~nm}$ and most of the particles had almost spherical geometry (see Fig. 6a. The HRTEM image, shown in Fig. 6b, indicated that carbon dots exhibited lattice fringes with a $\mathrm{d}$-spacing of $0.21 \mathrm{~nm}$, corresponding to the (100) plane lattice of graphite. [36]. Contrary to this, Ding et al. have reported a spacing of $0.32 \mathrm{~nm}$ for the carbon dots obtained from single-walled carbon nano tubes [37].

We also determined particle size distribution of N-CDs, using various TEM images (some images not shown in data) and selecting a number of particles randomly. The distribution curve, as shown in Fig. 6c, reveals that nearly, $42 \%$ particles had diameter in the range of 5-7 nm, while $26 \%$ of the carbon dots had diameter in the range of $3-5 \mathrm{~nm}$. In this way, nearly, $85 \%$ of the carbon dots had their diameter below $7 \mathrm{~nm}$. The small size of carbon dots had a better chance to enter into plant cells. Finally, the zeta potential of carbon dots was observed to be $-11.3 \mathrm{mV}$. The observed negative potential may be attributed to the presence of negatively charged carboxylate groups [38].
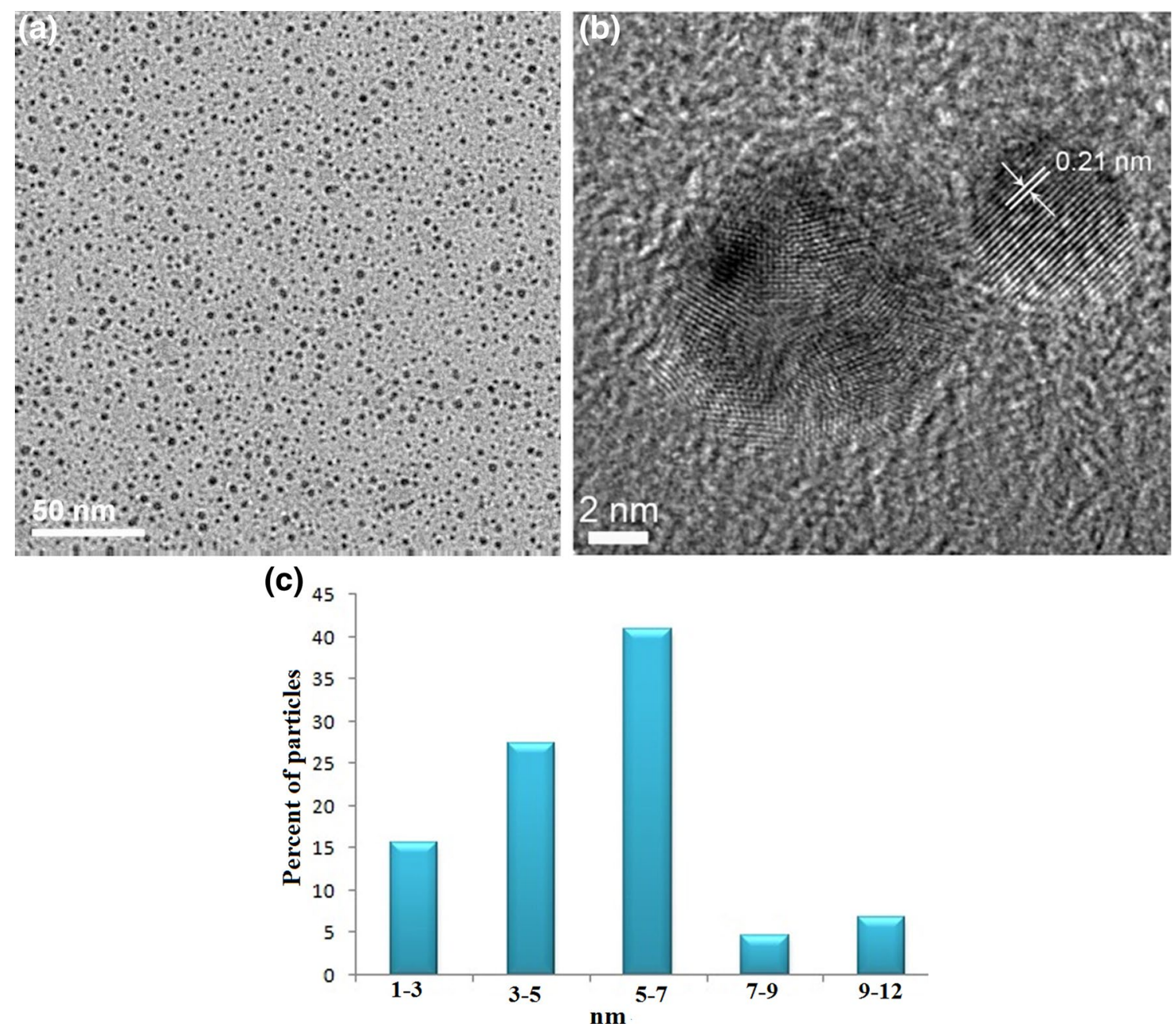

Fig. 6 a TEM image of N-CDs, (b) interplanar distance, and (c) particle size distribution 


\section{Emission spectra of $\mathrm{N}-\mathrm{CDs}$}

The photoluminescent emission spectra of N-carbon dots, at the excitation wavelengths of $260-340 \mathrm{~nm}$, are shown in Fig. 7. It can be observed that for the excitation wavelengths of 260-290 nm, no prominent peak is observed. However, as the excitation wavelength is further increased, relatively broader peak appears in the spectra and the strongest emission spectrum is observed for the excitation wavelength of $340 \mathrm{~nm}$. It is also noteworthy that a red shift in the emission peak from 420 to $450 \mathrm{~nm}$ is observed as the excitation wavelength increases from 300 to $340 \mathrm{~nm}$. This may be attributed to different sizes of $\mathrm{N}$-carbon dots and a distribution of different surface states due to the presence of different organic groups on the surface of carbon dots [39]. Similar results have also been reported by others. For example, Yang et al. prepared carbon dots from mangos teen and reported a red shift in the photoemission spectra with the increase of excitation wavelength from 290 to $470 \mathrm{~nm}$ [40]. In another work by $\mathrm{Wu}$ et al. tunable fluorescence emission, CQDs from chlorophyll were synthesized and their fluorescence emission spectroscopy was found to undergo red shift from 450

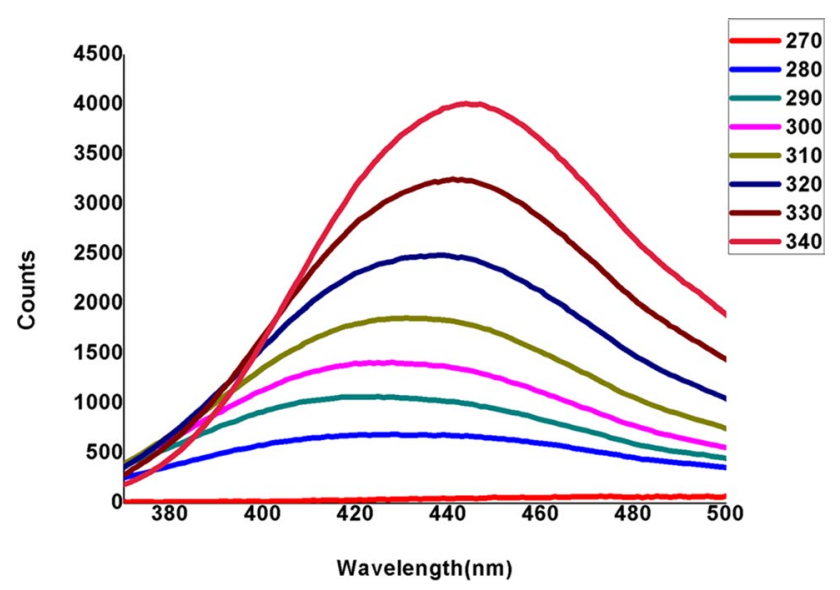

Fig. 7 Emission spectra of N-CDs to $520 \mathrm{~nm}$, as the excitation wavelengths increased from 360 to $460 \mathrm{~nm}$ [41]. However, there are several reports in which emission spectra do not show any shift with the change in the excitation wavelengths. For example, Fu et al. prepared arginine-modified carbon dots and reported luminescence peak around $470 \mathrm{~nm}$ at the excitation wavelength range of 320-560 nm [42]. In another report, graphene QDs were prepared by acidic oxidation and exfoliation of multi-walled carbon nanotubes (MWCNT), and their photoluminescent emission spectra were observed at the excitation wavelength range of $310-370 \mathrm{~nm}$, with strong peak at $560 \mathrm{~nm}$ at every excitation wavelength [43]. It was suggested that this could be attributed to the uniform particle size distribution of GQDs, having almost uniform size of $10 \mathrm{~nm}$.

\section{Fluorescence microscopic studies}

The particles were seen with blue emission under UV filter, red emission under green filter and green emission under the red filter, as shown in Fig. 8a-c. A wide range of fluorescence emission is highly advantageous and efficient compared to CQDs with single green fluorescence [44].The results suggests that the present CQDs could be a good alternative to tradition dyes for fluorescent labeling, bio-imaging, and bio-sensor applications.

\section{$\mathrm{N}-C D s$ ' insertion into leaf cells}

To investigate the uptake, transport, and distribution of nanoparticles in plants, and the impact of nanomaterials on plant function, the first key step is to deliver the nanoparticles into plants in vivo [45]. Uptake and accumulation of carbon nanotubes along with fullerenes and fullerol in edible and crop plants were previously reported [46]. The penetration of CNTs into the plant system is inversely proportional to its size. Perhaps, the large size of activated carbon particles is forbidden to enter the plant cell and, therefore, get adsorbed on the surface. The absorption of carbon nanomaterial depends mainly on its interaction with suspended organic
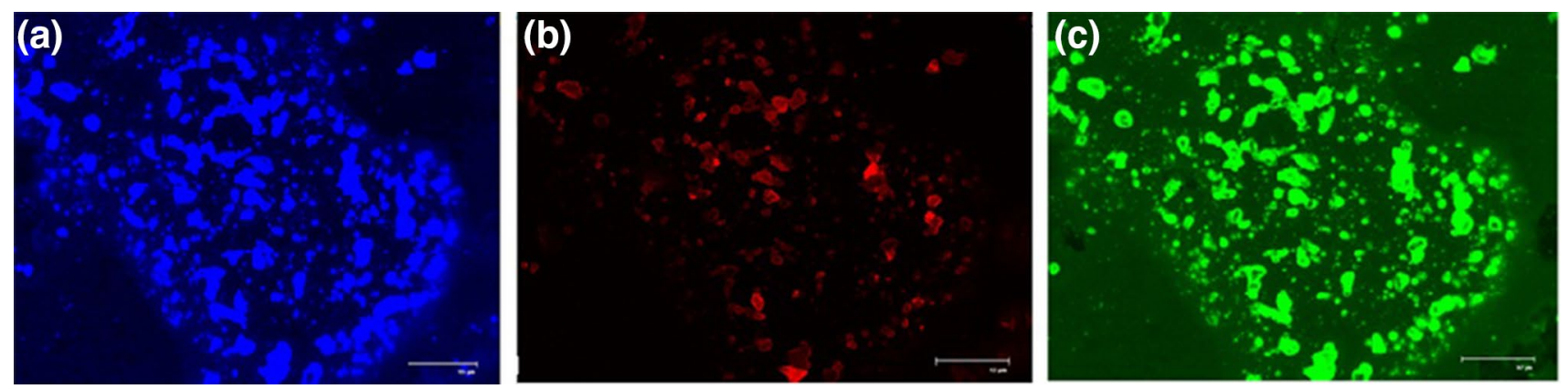

Fig. 8 Fluorescence images of N-CDs obtained (a) with blue emission under UV filter, (b) red emission under green filter, and (c) green emission under the red filter 
materials, its colloidal nature and the homo-heterogenous media which permit its smooth flow into the plant system.

Observations, based on confocal microscopy, Eichert et al. reported that nanoparticles, having diameter of $43 \mathrm{~nm}$, could penetrate the stomata leaf pores [47]. Similarly, Birbaum et al. used electronic and confocal microscopy to reveal that leaves of Zea mays, when subjected to an aqueous solution of $\mathrm{CeO}_{2}$ nanoparticles (10 ppm concentration) with an average diameter of $37 \mathrm{~nm}$, retained them appreciably with no sign of translocation to the stem [48].

In a study, Verma et al. revealed the connection between cell internalization and surface geometry of the NPs [49]. They found that CDs with homogeneous and unstructured surface were internalized primarily through energy-dependent endocytosis. As leaf cells remains in higher concentrations of CDs, even for short-time duration, they may cause alterations of membranes and other cell structures and molecules [50]. At low concentration, the number of N-CDs insertion increases with time; however, as the concentration increases, the insertion first increases then decreases, the reason for the same may be due to the change in the cytoplasmic condition at low concentration the number of $\mathrm{N}$-CDs in the cytoplasm is less, and hence, with increase in time, it increases, but as the concentration increases, the number of N-CDs in cytoplasm increases, thereby changing the cytoplasmic environment, i.e., the concentration of cytoplasmic fluid changes, which prevents the further insertion of N-CDs after a definite interval of time (Turgor Pressure). Since carbon nanotubes can stimulate growth, gene, and protein expression of aquaporin in tobacco cells [51].
It may also trigger the reproductive genes in similar other plants. The penetration of CNTs into the plant system is inversely proportional to its size, and it is the key factor to increase the plant growth and fruits. Perhaps, the large size of activated carbon particles is forbidden to enter the plant cell and, therefore, get adsorbed on the surface.

Structure of stomata, surrounding guard cells, and epidermal cells are visible in Fig. 9a. Insertion of N-CDs was clearly visible in guard cells. At minimum concentration (200 ppm), the penetration of N-CDs increased with time. In $200 \mathrm{ppm}$ concentration, maximum percent insertion (MPI) was obtained after $80 \mathrm{~min}$ (Fig. 9b). With increasing concentration of N-CDs, time of getting MPI reduced, in $600 \mathrm{ppm}$, it was $30 \mathrm{~min}$ (Fig. 9c), and in $800 \mathrm{ppm}$, it was $10 \mathrm{~min}$. Here, it is worth mentioning that as nearly $82 \%$ of the carbon nanoparticles possessed diameter below $10 \mathrm{~nm}$ (please see the particle size distribution curve shown previously), they could penetrate the cells easily.

\section{CDs' solutions used for immersion of leaves}

We also investigated the dynamic uptake of N-CDs by plant Guard cells of plant leaves when immersed in solutions of different concentrations of carbon dots. The results of kinetic insertion of carbon dots in guard cells are shown in Fig. 10a. It may be noticed that the percent insertion of $\mathrm{N}-\mathrm{CDs}$ into guard cells increases with time, attains a maximum value and then begins to decrease. It is also noteworthy that as the concentration of $\mathrm{N}$-CDs solution increases, the time required for attainment of maximum insertion decreases.
Fig. 9 a Microscopic view of leaf of Spinacia oleracea showing stomata with guard and epidermal cells; fluorescent $\mathrm{N}-\mathrm{CD}$ s in guard cells when the leaf was immersed in carbon dot solutions with concentrations of b 200 ppm, c 600 ppm, and d 800 ppm
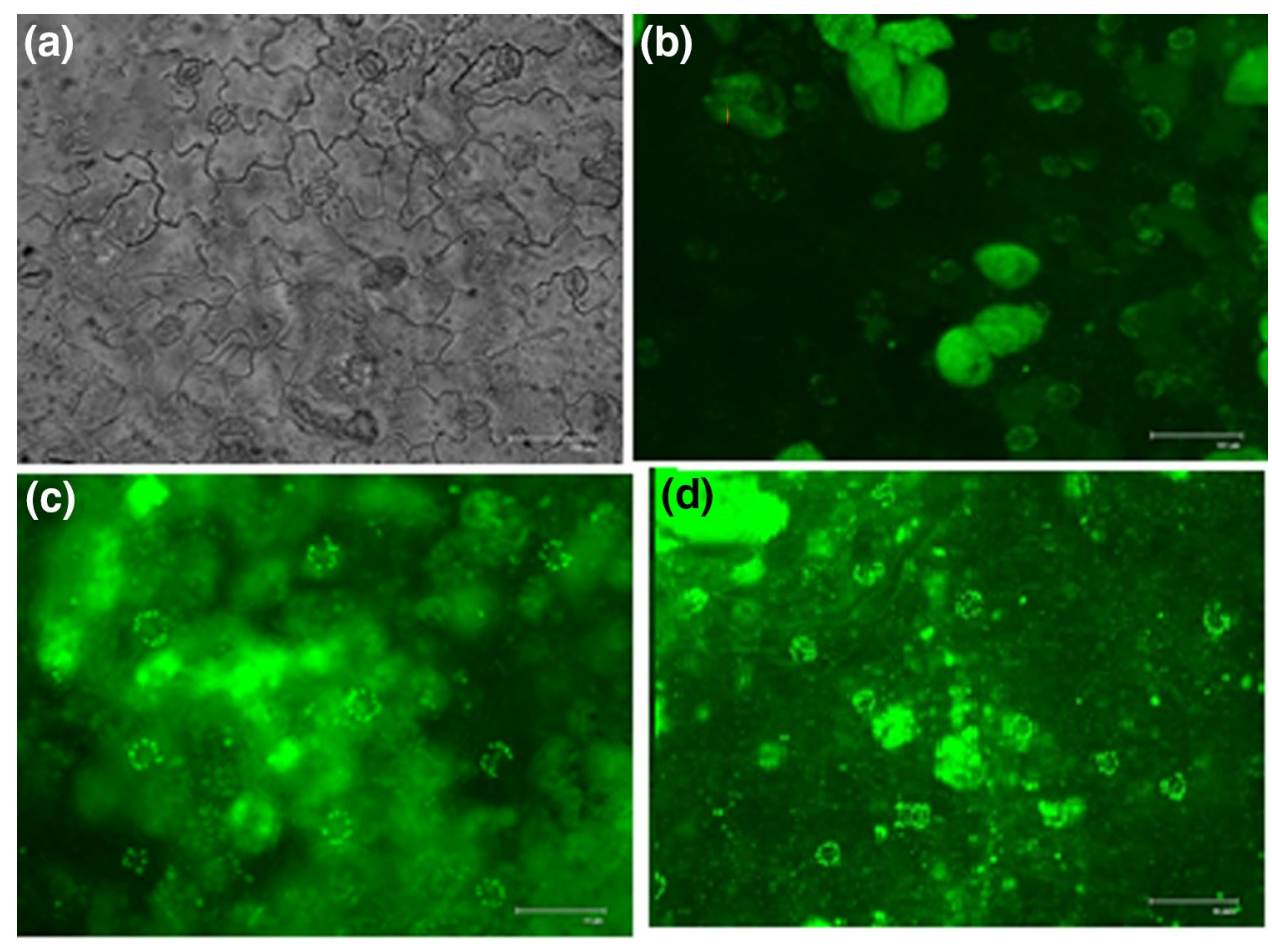

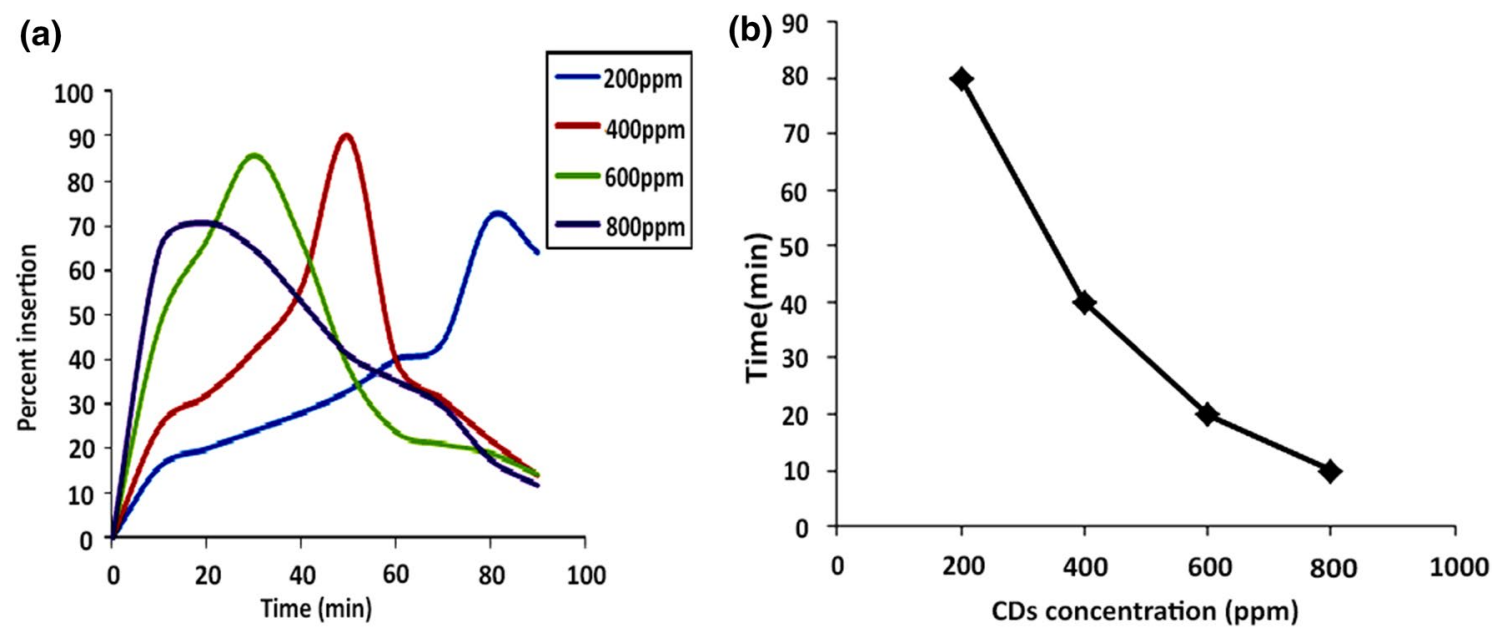

Fig. 10 a Dynamic uptake of N-CDs into cells when leaf is immersed in N-CDs' solution of different concentrations, b Maximum Percent Insertion (MPI) versus concentrations of N-CDs' solutions used for immersion of leaves

The observed decrease in the number of carbon dots after the attainment of MPI is attributable to the translocation of nanoparticles. The MPI for different CDs solutions, having concentration range of $200-800$ ppm, is shown in Fig. $10 \mathrm{~b}$. It may be noticed that as the concentration of CDs' solution increases, the time required for maximum percent insertion decreases.

Finally, the optical image of a plain and a CNP-loaded leaf is shown in Fig. 11a, b, respectively. It can be observed that carbon nanoparticles are accumulated to a greater extent around the Midrib as well as veins. It is attributable to the fact that CNPs are transported into the leaf system through
Midrib and veins network, rather than absorption through lamina.

\section{Conclusion}

The above study concludes that casein, a milk protein, can conveniently be converted into $\mathrm{N}$-carbon dots via microwave-assisted approach without using any capping and/ or passivating agent. The CDs are synthesized under mild conditions, without using any toxic chemicals. These particles show blue fluorescence under ultraviolet light. TEM
Fig. 11 Optical image of a plain and $\mathbf{b}$ N-CD-loaded leaf

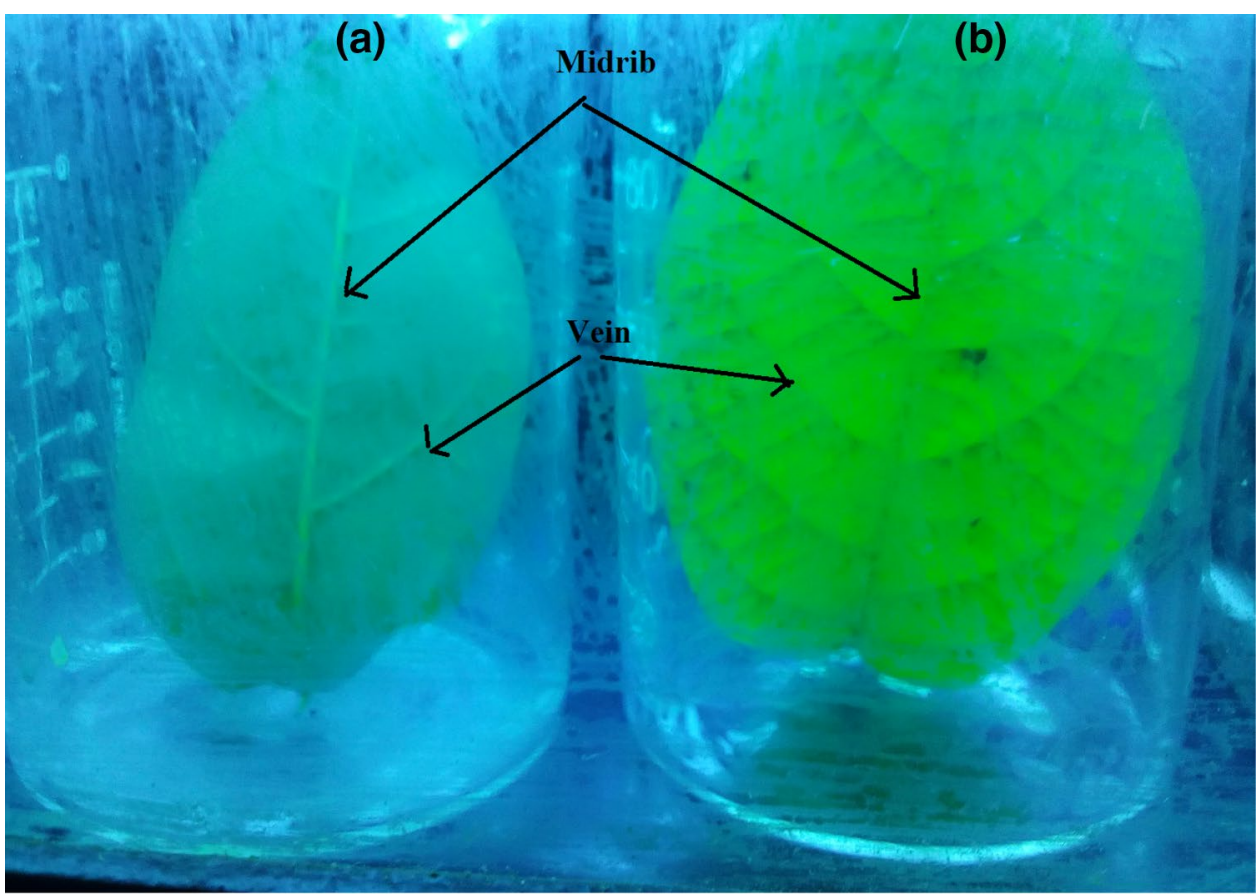


analysis and particle size distribution curve revealed that nearly, $85 \%$ of the particles had diameter below $10 \mathrm{~nm}$ and the particles had spherical geometry. The HRTEM analysis revealed that carbon dots exhibited lattice fringes with a d-spacing of $0.21 \mathrm{~nm}$, corresponding to the (100) plane lattice of graphite. The N-CDs show strong fluorescence when viewed through different filters. The fluorescence spectral studies indicated a red shift in the emission peak from 420 to $450 \mathrm{~nm}$, as the excitation wavelength increased from 300 to $340 \mathrm{~nm}$. Finally, impregnation of C-Dots was studied in Spinacia oleracea leaf. It was observed that as the concentration of CDs solution increased, percent insertion (PI) also increased, but the time required for maximal insertion decreased with increasing concentrations of CDs in the feed solutions. The absorption of N-CDs by plant cells may be used as a tool for cell imaging in plant-related diseases.

Open Access This article is distributed under the terms of the Creative Commons Attribution 4.0 International License (http://creativeco mmons.org/licenses/by/4.0/), which permits unrestricted use, distribution, and reproduction in any medium, provided you give appropriate credit to the original author(s) and the source, provide a link to the Creative Commons license, and indicate if changes were made.

\section{References}

1. Wang, H., Ning, G., He, X., Ma, X., Yang, F., Xu, Z., Zhao, S., $\mathrm{Xu}, \mathrm{C}$., Li, Y.: Carbon quantum dots derived by direct carbonization of carbonaceous microcrystals in mesophase pitch. Nanoscale (2018). https://doi.org/10.1039/c8nr07385f

2. Peng, X., Wang, R., Wang, T., Yang, W., Wang, H., Gu, W., Ye, L.: Carbon dots/prussian blue satellite/core nano composites for optical imaging and photo thermal therapy. ACS Appl. Mater. Interface. (2018). https://doi.org/10.1021/acsami.7b14972

3. Yang, J., Gao, G., Zhang, X., Ma, Y.H., Jia, H.R., Jiang, Y.W., Wang, Z., Wu, F.G.: Ultra small and photo stable nanotheranostic agents based on carbon quantum dots passivated with polyaminecontaining organosilane molecules. Nanoscale (2017). https://doi. org/10.1039/c7nr05613c

4. Yao, H., Li, J., Song, Y., Zhao, H., Wei, Z., Li, X., Jin, Y., Yang, B., Jiang, J.: Synthesis of ginsenoside Re-based carbon dots applied for bio imaging and effective inhibition of cancer cells. Int. J. Nanomed. (2018). https://doi.org/10.2147/ijn.s176176

5. Liu, C., Wang, R., Wang, B., Deng, Z., Jin, Y., Kang, Y., Chen, J.: Orange, yellow and blue luminescent carbon dots controlled by surface state for multicolor cellular imaging, light emission and illumination. Mikrochim. Acta. (2018). https://doi.org/10.1007/ s00604-018-3072-3.030

6. Wu, F., Su, H., Wang, K., Wong, W.K., Zhu, X.: Facile synthesis of $\mathrm{N}$-rich carbon quantum dots from porphyrins as efficient probes for bioimaging and biosensing in living cells. Int. J. Nanomedicine 12, 7375-7391 (2017)

7. Bandi, R., Dadigala, R., Gangapuram, B.R., Guttena, V.: Green synthesis of highly fluorescent nitrogen-doped carbon nano particles from Lantana camara berries for effective detection of lead(II) and bio imaging. J. Photochem. Photobiol. B Biol. (2018). https:// doi.org/10.1016/j.jphotobiol.2017.11.010

8. Zhang, D., Liu, C., Li, K., Chen, Y., Ruan, S., Zhang, X., Li, C.: Facilitated extrinsic majority carrier depletion and photo generated excitation dissociation in an annealing-free $\mathrm{ZnO}$ : $\mathrm{C}$ photo detector. Nanoscale (2018). https://doi.org/10.1039/c8nr0 0214b

9. Dutta Chowdhury, A., Ganganboina, A.B., Tsai, Y.C., Chiu, H.C., Doong, R.A.: Multifunctional GQDs-Concanavalin A@ $\mathrm{Fe} 3 \mathrm{O} 4$ nanocomposites for cancer cells detection and targeted drug delivery. Anal. Chim. Acta. (2018). https://doi.org/10.1016/j. aca.2018.04.029

10. Yao, H., Su, L., Zeng, M., Cao, L., Zhao, W., Chen, C., Du, B., Zhou, J.: Construction of magnetic-carbon-quantum-dots-probelabeled a poferritin nano cages for bio imaging and targeted therapy. Int. J. Nanomed. (2016). https://doi.org/10.2147/IJN. S108039

11. Gao, N., Yang, W., Nie, H., Gong, Y., Jing, J., Gao, L., Zhang, $\mathrm{X}$.: Turn-on theranostics fluorescent nano probe by electrostatic self-assembly of carbon dots with doxorubicin for targeted cancer cell imaging, in vivo hyaluronidase analysis, and targeted drug delivery. Biosens. Bioelectron. 96, 300307 (2017). https ://doi.org/10.1016/j.bios.2017.05.019

12. Prasad, R., Chauhan, D.S., Yadav, A.S., Devrukhkar, J., Singh, B., Gorain, M., Temgire, M., Bellare, J., Kundu, G.C., Srivastava, R.: A biodegradable fluorescent nanohybrid for photodriven tumor diagnosis and tumor growth inhibition. Nanoscale. (2018). https://doi.org/10.1039/c8nr05164j

13. Yuan, Y., Guo, B., Hao, L., Liu, N., Lin, Y., Guo, W., Li, X., Gu, B.: Doxorubicin-loaded environmentally friendly carbon nano particles as a novel drug delivery system for nucleus targeted cancer therapy. Coll. Surf. B Biointerface. 159, 349-359 (2017)

14. Zhang, Y., Fang, X., Zhao, H., Li, Z.: A highly sensitive and selective detection of $\mathrm{Cr}(\mathrm{VI})$ and ascorbic acid based on nitrogen-doped carbon dots. Talanta (2018). https://doi. org/10.1016/j.talanta.2018.01.027

15. Du, F., Gong, X., Lu, W., Liu, Y., Gao, Y., Shuang, S., Xian, M., Dong, C.: Bright-green-emissive nitrogen-doped carbon dots as a nano probe for bifunctional sensing, its logic gate operation and cellular imaging. Talanta (2018). https://doi.org/10.1016/j. talanta.2017.11.030

16. Zhang, Y., Yuan, R., He, M., Hu, G., Jiang, J., Xu, T., Zhou, L., Chen, W., Xiang, W., Liang, X.: Multicolor nitrogen-doped carbon dots: tunable photoluminescence and sandwich fluorescent glass-based light-emitting diodes. Nanoscale (2017). https ://doi.org/10.1039/c7nr05363k

17. Wang, N., Zheng, A.Q., Liu, X., Chen, J.J., Yang, T., Chen, M.L., Wang, J.H.: Deep eutectic solvent assisted preparation of nitrogen/chloride doped carbon dots for intracellular biological sensing and live cell imaging. ACS Appl. Mater. Interfaces (2018). https://doi.org/10.1021/acsami.8b00947

18. Tan, W., Fu, R., Ji, H., Kong, Y., Xu, Y., Qin, Y.: Preparation of nitrogen-doped carbon using graphene quantum dotschitosan as the precursor and its super capacitive behaviors. Int. J Biol. Macromol. (2018). https://doi.org/10.1016/j.ijbio mac.2018.02.014

19. Zhao, C., Jiao, Y., Hua, J., Yang, J., Yang, Y.: Hydrothermal synthesis of nitrogen-doped carbon quantum dots as fluorescent probes for the detection of dopamine. J. Fluoresc. (2018). https:// doi.org/10.1007/s10895-017-2189-9

20. Li, J., Zuo, G., Pan, X., Wei, W., Qi, X., Su, T., Dong, W.: Nitrogen-doped carbon dots as a fluorescent probe for the highly sensitive detection of $\mathrm{Ag}^{+}$and cell imaging. Luminescence (2018). https://doi.org/10.1002/bio.3407

21. Liao, S., Zhao, X., Zhu, F., Chen, M., Wu, Z., Song, X., Yang, H., Chen, X.: Novel S, N-doped carbon quantum dot-based "off-on" fluorescent sensor for silver ion and cysteine. Talanta (2018). https ://doi.org/10.1016/j.talanta.2017.12.040

22. Wang, P., Jin, S., Guo, H., Zhao, L., Ren, F.: The pressureinduced, lactose-dependent changes in the composition and size 
of casein micelles. Food Chem. (2015). https://doi.org/10.1016/j. foodchem.2014.09.159

23. Li, H., Kang, Z., Liu, Y., Lee, S.-T.: Carbon nanodots: synthesis, properties and applications. J. Mater. Chem. (2012). https://doi. org/10.1039/c2jm34690g

24. Li, Hua, Shao, F., Zou, S., Wang, Q., Huang, H., Feng, J., Wang, A.: Microwave-assisted synthesis of N, P-doped carbon dots for fluorescent cell imaging. Microchimica. Acta. (2016). https://doi. org/10.1007/s00604-015-1714-2

25. He, G., Xu, M., Shu, M., Li, X., Yang, Z., Zhang, L., Su, Y., Hu, N., Zhang, Y.: Rapid solid-phase microwave synthesis of highly photoluminescent nitrogen-doped carbon dots for $\mathrm{Fe} 3$ + detection and cellular bioimaging. Nanotechnology 27, 395706 (2016)

26. Tabaraki, R., Sadeghinejad, N.: Microwave assisted synthesis of doped carbon dots and their application as green and simple turn off-on fluorescent sensor for mercury (II) and iodide in environmental samples. Ecotoxicol. Environ. Saf (2018). https://doi. org/10.1016/j.ecoenv.2018.01.059

27. Wang, N., Zheng, A.Q., Liu, X., Chen, J.J., Yang, T., Chen, M.L., Wang, J.H.: Deep eutectic solvent assisted preparation of nitrogen/ chloride doped carbon dots for intracellular biological sensing and live cell imaging. ACS Appl. Mater. Interfaces (2018). https://doi. org/10.1021/acsami.8b00947

28. PtičekSiročić, A., Kratofil Krehula, L., Katančić, Z., HrnjakMurgić, Z.: Characterization of casein fractions comparison of commercial casein and casein extracted from cow's milk. Chem. Biochem. Eng. Q. (2016). https://doi.org/10.15255/CABEQ .2015 .2311

29. Sharma, A., Gadly, T., Neogy, S., Ghosh, S.K., Kumbhakar, M.: Origin of excitation dependent fluorescence in carbon nano dots. J. Phys. Chem. Lett. (2017). https://doi.org/10.1021/acs.jpcle tt.6b01791

30. Gowthaman, N.S.K., Sinduja, B., Karthikeyan, R., Rubini, K., Abraham John, S.: Fabrication of nitrogen-doped carbon dots for screening the purine metabolic disorder in human fluids. Biosens. Bioelectron. (2017). https://doi.org/10.1016/j.bios.2017.02.034

31. Gao, N., Yang, W., Nie, H., Gong, Y., Jingm, J., Gao, L., Zhang, $\mathrm{X}$.: Turn-on theranostic fluorescent nano probe by electrostatic self-assembly of carbon dots with doxorubicin for targeted cancer cell imaging, in vivo hyaluronidase analysis, and targeted drug delivery. Biosens. Bioelectron. (2017). https://doi.org/10.1016/j. bios.2017.05.019

32. Liu, Y., Liu, C.Y., Zhang, Z.Y.: Synthesis and surface photochemistry of graphitized carbon quantum dots. J. Coll. Interface Sci. (2011). https://doi.org/10.1016/j.jcis.2011.01.065

33. Lu, S., Guo, S., Xu, P., Li, X., Zhao, Y., Gu, W., Xue, M.: Hydrothermal synthesis of nitrogen-doped carbon dots with real-time live-cell imaging and blood-brain barrier penetration capabilities. Int. J. Nanomed. (2016). https://doi.org/10.2147/ijn.s119252

34. Liu, Y., Zhou, Q., Yuan, Y., Wu, Y.: Hydrothermal synthesis of fluorescent carbon dots from sodium citrate and polyacrylamide and their highly selective detection of lead and pyrophosphate. Carbon (2017). https://doi.org/10.1016/j.carbon.2017.01.035

35. He, J., He, Y., Zhuang, J., Zhang, H., Lei, B., Liu, Y.: Carbon dotsbased fluorescent probe for "off-on" sensing of $\mathrm{Hg}(\mathrm{II})$ and $\mathrm{I}^{-}$. Opt. Materials (2016). https://doi.org/10.1016/j.bios.2015.12.084

36. Zhang, Y., Feng, J., He, M., Jiang, J., Xu, T., Zhou, L., Chen, W., Xiang, W., Liang, X.: Efficient and stable white fluorescent carbon dots and CD-based glass thin-films via screen-printing technology for use in W-LEDs. RSC Adv. (2017). https://doi.org/10.1039/ c7ra09924j
37. Ding, H., Cheng, L., Ma, Y., Kong, J., Xiong, H.: Luminescent carbon quantum dots and their application in cell imaging. New J. Chem. (2013). https://doi.org/10.1039/c3nj00366c

38. Das, P., Jana, N.R.: Highly colloidally stable hyper branched poly glycerol grafted red fluorescent silicon nanoparticle as bio imaging probe. ACS Appl. Mater. Interfaces (2014). https://doi. org/10.1021/am406061x

39. Xu, X.Y., Ray, R., Gu, Y.L., Ploehn, H.J., Gearheart, L., Raker, K., Scrivens, W.A.: Electrophoretic analysis and purification of fluorescent single-walled carbon nanotube fragments. J. Am. Chem. Soc. (2004). https://doi.org/10.1021/ja040082h

40. Wu, Z.L., Lu, Z.X., Yuan, Y.H.: Carbon dots: materials, synthesis, properties and approaches to long-wavelength and multicolor emission. J. Mater. Chem. B. (2017). https://doi.org/10.1039/ c7tb00363c

41. Wu, X., Song, Y., Yan, X., Zhu, C., Ma, Y., Du, D., Lin, Y.: Carbon quantum dots as fluorescence resonance energy transfer sensors for organophosphate pesticides determination. Biosens. Bioelectron. (2017). https://doi.org/10.1016/j.bios.2017.03.010

42. Fu, C., Qian, K., Fu, A.: Arginine-modified carbon dots probe for live cell imaging and sensing by increasing cellular uptake efficiency. Mater. Sci. Eng. C Mater. Biol. Appl. (2017). https:// doi.org/10.1016/j.msec.2017.03.084

43. Iannazzoa, D., Pistonea, A. O., Salamòa, M., Galvagnoa, S., Romeo, R., Giofre, S. V., Branca, C. O., Visalli, G., Pietro, A. D.: Int. J. Pharmaceutics (2017). https://doi.org/10.1016/j.ijpha rm.2016.12.060

44. Shankaran, D.R., Thambiraj, S.: Green synthesis of highly fluorescent carbon quantum dots from sugarcane bagasse pulp. Appl Surface Sci. 390, 435-443 (2016)

45. Wu, H., Santana, I., Dansie, J., Giraldo, J.P.: In vivo delivery of nanoparticles into plant leaves. Curr. Protoc. Chem. Biol. 9, 269-284 (2017). https://doi.org/10.1002/cpch.29

46. Siddiqi, K.S., Husen, A.: Carbon and fullerene nanomaterials in plant system. J. Nanobiotechnol. (2014). https://doi. org/10.1186/1477-3155-12-16

47. Eichert, T., Kurtz, A., Steiner, U., Goldbach, H.E.: Size exclusion limits and lateral heterogeneity of the stomatal foliar uptake pathway for aqueous solutes and water-suspended nanoparticles. Physiol. Plant. (2008). https://doi.org/10.1111/j.1399-3054.2008.01135

48. Birbaum, K., Brogioli, R., Schellenberg, M., Martinoia, E., Stark, W.J., Günther, D., Limbach, L.K.: No evidence for cerium dioxide nanoparticle translocation in maize plants. Environ. Sci. Technol. (2010). https://doi.org/10.1021/es101685f

49. Verma, A., Uzun, O., Hu, Y., Han, H.S., Watson, N., Chen, S., Irvine, D.J., Stellacci, F.: Surface-structure-regulated cell-membrane penetration by monolayer-protected nanoparticles. Nat. Mater (2008). https://doi.org/10.1038/nmat2202

50. Saxena, J., Sharma, M.M., Gupta, S., Singh, A.: Emerging role of fungi in nanoparticle synthesis and their applications world. J. Pharmacy Pharmaceutical Sci. 3, 1586-1613 (2014)

51. Khodakovskaya, M.V., De Silva, K., Biris, A.S.E., Villagarcia, D.H.: Carbon nanotubes induce growth enhancement of tobacco cells. ACS Nano (2012). https://doi.org/10.1021/nn204643g

Publisher's Note Springer Nature remains neutral with regard to jurisdictional claims in published maps and institutional affiliations. 